\title{
A Regional Time-of-Use Electricity Price Based Optimal Charging Strategy for Electrical Vehicles
}

\author{
Jun Yang ${ }^{1}$, Jiejun Chen ${ }^{1, *}$, Lei Chen ${ }^{1}$, Feng Wang ${ }^{2}$, Peiyuan $\mathrm{Xie}^{3}$ and Cilin Zeng ${ }^{3}$ \\ 1 School of Electrical Engineering, Wuhan University, Wuhan 430072, China; JYang@whu.edu.cn (J.Y.); \\ stclchen1982@163.com (L.C.) \\ 2 Computer School of Wuhan University, Wuhan 430072, China; fengwang@whu.edu.cn \\ 3 State Grid Hunan Power Supply Company, Changsha 410007, China; xie_peiyuan@163.com (P.X.); \\ clzenghust@126.com (C.Z.) \\ * Correspondence: chenjiejun@whu.edu.cn; Tel.: +86-27-6877-6346
}

Academic Editors: Michael Gerard Pecht and Ximing Cheng

Received: 30 May 2016; Accepted: 8 August 2016; Published: 24 August 2016

\begin{abstract}
With the popularization of electric vehicles (EVs), the out-of-order charging behaviors of large numbers of EVs will bring new challenges to the safe and economic operation of power systems. This paper studies an optimal charging strategy for EVs. For that a typical urban zone is divided into four regions, a regional time-of-use (RTOU) electricity price model is proposed to guide EVs when and where to charge considering spatial and temporal characteristics. In light of the elastic coefficient, the user response to the RTOU electricity price is analyzed, and also a bilayer optimization charging strategy including regional-layer and node-layer models is suggested to schedule the EVs. On the one hand, the regional layer model is designed to coordinate the EVs located in different time and space. On the other hand, the node layer model is built to schedule the EVs to charge in certain nodes. According to the simulations of an IEEE 33-bus distribution network, the performance of the proposed optimal charging strategy is verified. The results demonstrate that the proposed bilayer optimization strategy can effectively decrease the charging cost of users, mitigate the peak-valley load difference and the network loss. Besides, the RTOU electricity price shows better performance than the time-of-use (TOU) electricity price.
\end{abstract}

Keywords: electric vehicles; user responsivity; optimization scheduling; RTOU electricity price model; regional layer model; node layer model

\section{Introduction}

EVs represent a promising technology due to their environmental friendliness and potential to reduce the dependence on fossil fuels [1]. However, the integration of massive numbers of EVs is still regarded as a great challenge for electric power systems. The random charging behaviors of large-scale EVs in spatial and temporal domains may lead to a series of problems in the power grid, such as power congestion, under-voltage, and grid instability [2,3]. Considering that EVs can represent the distributed and mobile power demands in the near future, it's meaningful and valuable to study the optimal charging strategy of EVs [4,5], so as to promote the large-scale application of EVs.

At present, studies on the optimal scheduling of EVs are generally performed considering spatial and temporal characteristics. Some optimization models have been proposed to coordinate EV users in the temporal domain [6-9]. In [6], to optimize the objective functions including the loss and cost of purchased energy, an optimization approach to devise an efficient management strategy is proposed for EVs. In [7], a multi-objective scheduling of EVs in a smart distribution system is proposed, so as to minimize the total operation cost and emissions. In [8], to improve the security and economics of the grid operation, a model concerning with optimal power flow, statistic characteristics of EVs, 
EV owners' degree of satisfaction, and the power grid cost is suggested. In [9], the optimal charging strategy of EVs is suggested to smooth the daily curve, and the results can confirm its effectiveness.

Regarding the optimization models which can coordinate EV users in spatial domain, a few works have been done to date [10-12]. In [10], to reduce the impacts of disordered charging behaviors on the distribution network, multi-objective optimization including charging time, distance and dispatching charging load is investigated, and the complete EV charging load spatial allocation can be achieved. In [11,12], the corresponding authors discuss the charging strategies of plug-in EVs to improve the economic operation of the power grid and highlight the users' benefits. In $[13,14]$, the optimization strategies are based on the bilayer optimization at transmission and distribution system levels, and herein optimizing the peak-valley difference and reducing the network loss can be achieved, respectively. However, the interests of EV charging stations are ignored in the aforementioned works, and the incentive measures guiding the EVs to charge are not taken into account.

In fact, the electricity price is an effective means to guide the orderly charging behaviors of EVs. The pricing scheme conveys price and quantity information to the load aggregator to control plug-in EV fleet charging $[15,16]$. To apply peak shaving for power grid by scheduling the charging behaviors of EVs, the peak-valley TOU electricity price is discussed in [17]. The TOU electricity price is discussed in [18], and the optimal scheduling models of EVs based on the TOU price is proposed in $[19,20]$.

The coordination strategies of plug-in EVs charging in smart grids based on real-time electricity price are proposed in [21,22], and this strategies are able to minimize the power losses and improve the voltage profiles. However, with the development of electricity market, charging stations will arrange certain electricity price policy to attract EVs to charge, and meanwhile the electricity price policy will be different in the temporal and spatial domains. Note that, the traditional electricity price can't satisfy this requirement. Therefore, a new electricity price policy considering temporal and spatial characteristics must be studied. In addition, the charging behaviors of EVs may be absolutely stochastic for charging station in reality, so only partial EVs will respond to the electricity price to charge in related stations. Consequently, EV user responsivity to electricity price must be considered in the optimal strategy of EVs. Table 1 generalizes the objectives of aforementioned works on the optimal scheduling of EVs. In this paper, our research group proposes a regional time-of-use (RTOU) electricity price-based optimal charging strategy for EVs considering the user responsivity. For that a typical urban zone is divided into four regions, the RTOU electricity price model can guide EVs when and where to charge, and also a bi-layer optimization charging strategy including regional-layer and node-layer models is suggested to schedule the EVs. The paper is organized as follows: a RTOU electricity price model is built in Section 2. Section 3 analyses the user responsivity to the RTOU electricity price. A bi-layer optimization model for coordinating EVs is proposed in Section 4. Section 5 is devoted to simulations of an IEEE 33-bus distribution network, and the performance of the proposed optimal charging strategy is verified. Finally, conclusions are drawn in Section 6.

Table 1. The researches on the optimal scheduling of EVs.

\begin{tabular}{|c|c|c|c|}
\hline Research & Perspective & Literature & Objective Function \\
\hline \multirow{7}{*}{$\begin{array}{l}\text { Scheduling } \\
\text { Strategy }\end{array}$} & \multirow{4}{*}{$\begin{array}{l}\text { Temporal } \\
\text { domain }\end{array}$} & {$[6]$} & $\begin{array}{l}\text { (1) power losses } \\
\text { (2) the cost of purchased energy }\end{array}$ \\
\hline & & [7] & (1) the total operational costs and emissions \\
\hline & & [8] & $\begin{array}{l}\text { (1) power loss } \\
\text { (2) adjustment frequency for power grid control equipment } \\
\text { (3) the smoothness for the power daily load curve } \\
\text { (4) EV owners' degree of satisfaction }\end{array}$ \\
\hline & & [9] & (1) peak-valley difference \\
\hline & \multirow{3}{*}{ Spatial domain } & [10] & $\begin{array}{l}\text { (1) system charging time } \\
\text { (2) system charging capacity } \\
\text { (3) dispatching charging load }\end{array}$ \\
\hline & & {$[11]$} & $\begin{array}{l}\text { (1) generation cost } \\
\text { (2) network losses }\end{array}$ \\
\hline & & [12] & (1) the utilization of existing networks \\
\hline
\end{tabular}


Table 1. Cont.

\begin{tabular}{|c|c|c|c|}
\hline Research & Perspective & Literature & Objective Function \\
\hline \multirow{2}{*}{$\begin{array}{l}\text { Scheduling } \\
\text { Strategy }\end{array}$} & \multirow{2}{*}{$\begin{array}{l}\text { Temporal and } \\
\text { Spatial domain }\end{array}$} & [13] & $\begin{array}{l}\text { (1) First level: the discharging cost of EV, charging station corresponding } \\
\text { transformer loading } \\
\text { (2) Second level: network Losses }\end{array}$ \\
\hline & & [14] & $\begin{array}{l}\text { (1) transmission system: fuel cost; the } \mathrm{PM}_{2.5} \text { emission of a thermal unit; the } \\
\text { start-up and shut-down cost of thermal unit; charging cost; wind curtailment cost } \\
\text { (2) distribution system: network Losses }\end{array}$ \\
\hline \multirow{5}{*}{$\begin{array}{l}\text { Incentive } \\
\text { Measures }\end{array}$} & $\begin{array}{l}\text { Peak-Valley } \\
\text { TOU }\end{array}$ & [17] & (1) peak-valley difference \\
\hline & \multirow{2}{*}{ TOU } & [19] & (1) energy cost \\
\hline & & [20] & (1) charging cost \\
\hline & \multirow{2}{*}{ Real-Time } & [21] & $\begin{array}{l}\text { (1) the difference between load curve and ideal load curve } \\
\text { (2) network Losses }\end{array}$ \\
\hline & & [22] & (1) the total cost for charging all EVs within the day \\
\hline Conclusions & \multicolumn{3}{|c|}{$\begin{array}{l}\text { The new electricity price policy must be studied considering both temporal and spatial characteristics. Also, EV user } \\
\text { responsivity to electricity price and the interests of EV charging station must be considered. }\end{array}$} \\
\hline
\end{tabular}

\section{The Model of RTOU Electricity Price}

In light of the commercial operation demands of EVs, different charging stations may need different electricity prices [23]. Thus, a RTOU electricity price model considering temporal and spatial characteristics is discussed in this section. Compared with TOU electricity prices, the RTOU electricity prices in different regions are different. In a certain region, the RTOU electricity price consists of four electricity price levels [24], and the following equation can be obtained:

$$
\rho= \begin{cases}\rho_{1} & P_{\min } \leq P \leq P_{1} \\ \rho_{2} & P_{1} \leq P \leq P_{2} \\ \rho_{3} & P_{2} \leq P \leq P_{3} \\ \rho_{4} & P_{3} \leq P \leq P_{\max }\end{cases}
$$

where $\rho$ is the electricity price; $\rho_{1}, \rho_{2}, \rho_{3}$ and $\rho_{4}$ are the four-level electricity prices, respectively; $P$ is the daily load; $P_{\min }$ and $P_{\max }$ are the minimum and maximum daily loads in a day, respectively.

The values of $\rho_{1}, \rho_{2}, \rho_{3}$ and $\rho_{4}$ should be limited in a certain range according to the levels of user consumption. $\rho_{\min }$ is set to guarantee the benefits of the power grid considering commodity attribute of the electric power; $\rho_{\max }$ is set to guarantee the benefits of the EV users considering user acceptance for the electricity price. Meanwhile, the revenue of the power grid must be included:

$$
\begin{gathered}
\rho_{\min }<\rho_{1}<\rho_{2}<\rho_{3}<\rho_{4}<\rho_{\max } \\
\sum_{j=1}^{M} \sum_{t=1}^{T} P_{t}^{a, j} \rho_{t}^{j} \geq C_{0}
\end{gathered}
$$

where $\rho_{\min }$ and $\rho_{\max }$ are the minimum and maximum electricity prices, respectively. $P_{t}^{a, j}$ is the load at time $t$ in zone $j$ after the application of RTOU electricity prices. $M$ is the number of zones, and $T$ is the duration, with the default value of 24 . $C_{0}$ is the revenue of power grid before the application of RTOU electricity price:

$$
C_{0}=\sum_{t=1}^{T} P_{t}^{b} \rho_{0}
$$

where $P_{t}^{b}$ and $\rho_{0}$ are the load at time $t$ and the electricity price before the application of the RTOU electricity price, respectively. 
The relationship between the electricity price levels and the electricity power is expressed as:

$$
P_{i+1}=P_{i}+\Delta P
$$

where $\Delta P$ is the difference of the lower or upper load boundary between the adjacent electricity price level, and it can be obtained by investigating local residents' consumption habits and payment abilities.

In a way, $\Delta P$ can be simplified as:

$$
\Delta P=\frac{P_{\max }-P_{\min }}{n}
$$

where $n$ is the number of electricity price levels, and its value is set as 4 .

Figure 1 shows the RTOU electricity price model. The load curve is divided into four levels according to the maximal and minimal values of load level.

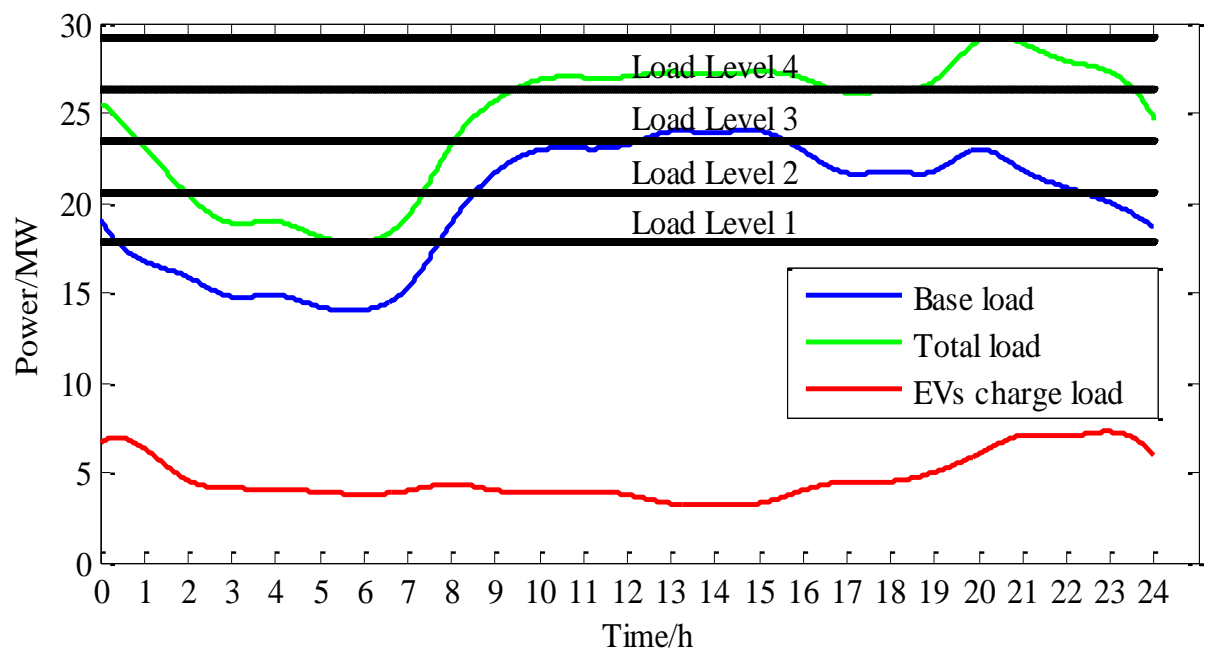

Figure 1. The divided standard of RTOU electricity price model.

The four charging scenarios [25] include uncontrolled charging, delayed charging, off-peak charging and continuous charging. The typical urban region consists of an industrial zone, a commercial zone, a residential zone and an office zone. In the uncontrolled charging case, EVs start to charge as soon as they are plugged in, and stop when the battery is fully charged. The delayed charging case is similar to the uncontrolled charging scenario. However, it requires only a modest infrastructure increase to delay initiation of household charging until 10 p.m. The off-peak charging scenario can provide a charging signal to lead EVs to charge in the optimal time for lower charging cost. For the continuous charging scenario, it assumes that the vehicle is continuously charged whenever it is not in motion. In view of the four zones and four charging modes, there are 16 charging scenarios. Since the analysis method for all of the scenarios is the same, one scenario is selected to investigate the characteristics, and the demonstrative scenario is shown in Figure 2. 


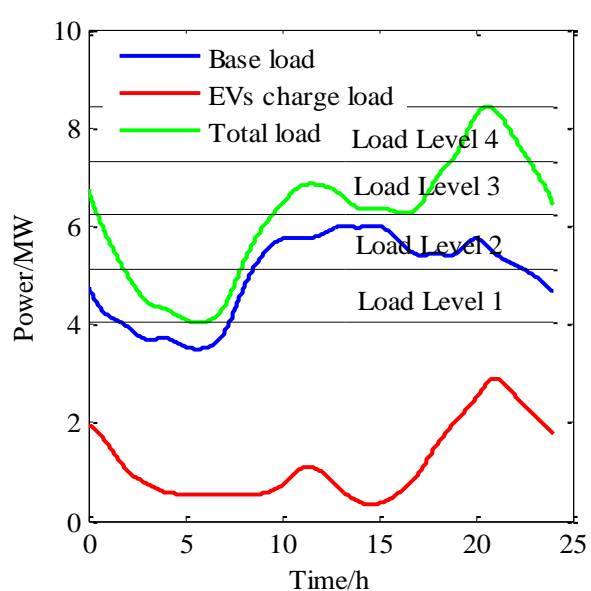

(a)

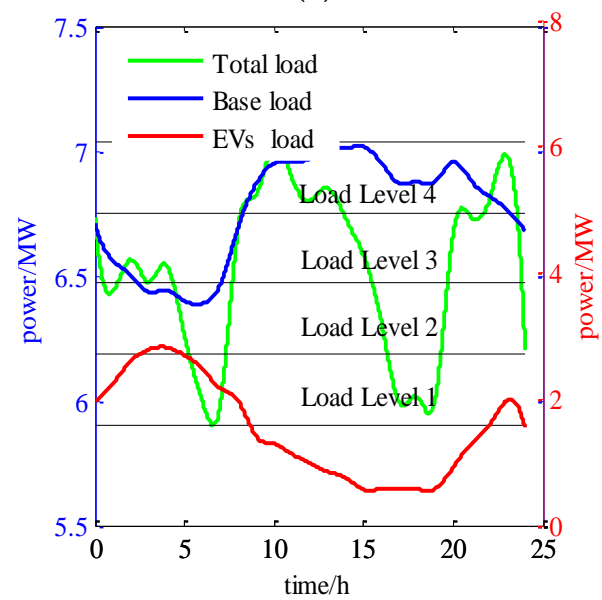

(c)

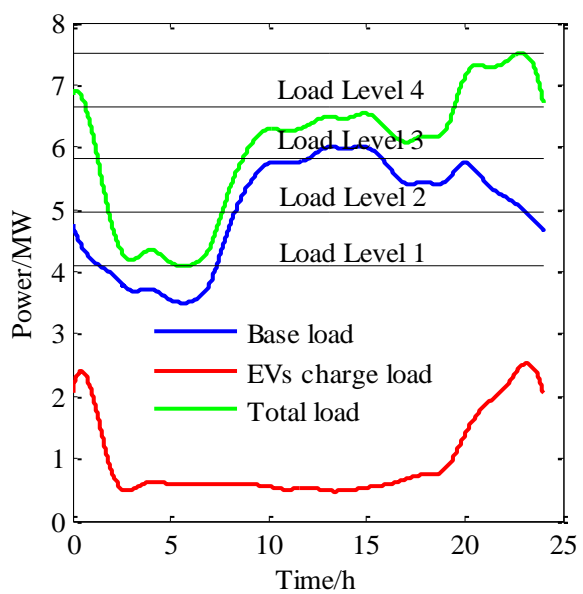

(b)

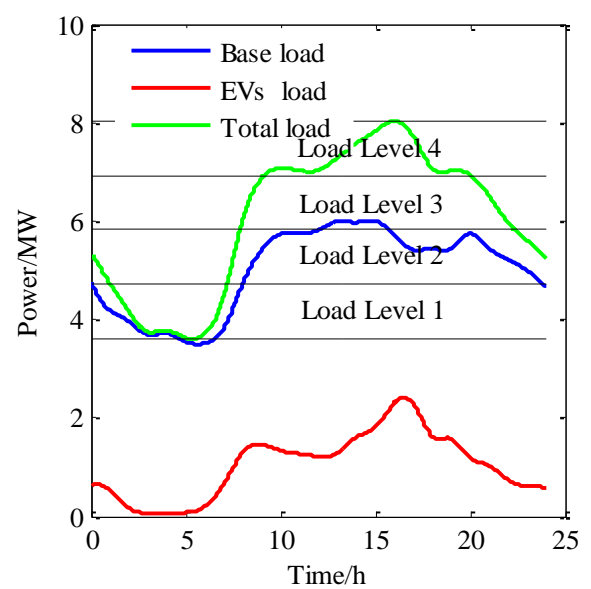

(d)

Figure 2. The demonstrative scenario of typical regional load curves. (a) The residential region load curve in the uncontrolled charging mode; (b) The office region load curve in delayed charging mode; (c) The industrial region load curve in off-peak charging mode; (d) The commercial zone region curve in continuous charging mode.

\section{The User Responsivity to the RTOU Electricity Price}

In fact, many factors will affect the charging behaviors of EVs [26], such as the price policies, EV charging scenarios, user's driving habits, SOC of batteries, and external environment. However, the purpose of EVs changing charging habits is to gain more economic benefits [27], and these interests are reflected in the electricity price. In this section, the electricity price is pointedly taken into account. Price elasticity [28] indicates the relationship between the electricity price and the number of responsive EVs, so the phenomenon of EV users' response to electricity price can be described as follows:

$$
\frac{\Delta N}{N}=\varepsilon \frac{\Delta \rho}{\rho_{0}}
$$

where $\Delta \rho$ is the variation of the electricity price, $\rho_{0}$ is the original electricity price; $\Delta N$, which represents the electricity consumption of EVs, is the variation of the number of charging EVs. $N$ is the original number of charging EVs; $\varepsilon$ is the elasticity coefficient.

In general, the EV users' responses will be affected by the price at the current time and the prices at other time. Meanwhile, after the application of the RTOU electricity prices, different regions have different electricity prices, so EV users' responses are not only related to the current regional price, 
but also affected by the price of other regions. Therefore, the regional self-elasticity coefficients and the cross-elasticity coefficients are expressed as follows:

$$
\begin{aligned}
& \frac{\Delta N_{t t}^{j j}}{N 0_{t}^{j}}=\varepsilon_{t t}^{j j} \frac{\Delta \rho_{t}^{j}}{\rho_{0}} \\
& \frac{\Delta N_{t s}^{j j}}{N N_{t}^{j}}=\varepsilon_{t s}^{j j} \frac{\Delta \rho_{s}^{j}}{\rho_{0}} \\
& \frac{\Delta N_{t t}^{j h}}{N 0_{t}^{j}}=\varepsilon_{t t}^{j h} \frac{\Delta \rho_{t}^{h}}{\rho_{0}} \quad h \neq j \\
& \frac{\Delta N_{t s}^{h}}{N 0_{t}^{j}}=\varepsilon_{t s}^{j h} \frac{\Delta \rho_{s}^{h}}{\rho_{0}} \quad h \neq j
\end{aligned}
$$

To simplify the calculation, the current regional and other regional mutual-elastic coefficients on different periods are converted into self-elasticity coefficients on a single period:

$$
\begin{aligned}
& \varepsilon_{t}^{j j}=\sum_{s=1}^{T} \varepsilon_{t s}^{j j} \frac{\Delta \rho_{s}^{j}}{\Delta \rho_{t}^{j}} \\
& \varepsilon_{t}^{j h}=\sum_{s=1}^{T} \varepsilon_{t s}^{j h} \frac{\Delta \rho_{s}^{h}}{\Delta \rho_{t}^{j}} \quad h \neq j
\end{aligned}
$$

where $\varepsilon_{t}^{j j}$ and $\varepsilon_{t}^{j h}$ are the current regional and other regional elasticity coefficients at $t$ in zone $j$, respectively.

The EVs charging elasticity coefficients of the current region and other regions are denoted as:

$$
\begin{aligned}
& \frac{\Delta N_{t}^{j j}}{N 0_{t}^{j}}=\varepsilon_{t}^{j j} \frac{\Delta \rho_{t}^{j}}{\rho_{0}} \quad j=1,2,3,4 \\
& \frac{\Delta N_{t}^{h h}}{N 0_{t}^{j}}=\varepsilon_{t}^{j h} \frac{\Delta \rho_{t}^{j}}{\rho_{0}} \quad h \neq j
\end{aligned}
$$

where $\mathrm{NO}_{t}^{j}$ is the original number of EVs charging at time $t$ in zone $j$.

Considering the influence of current regional and other regional elasticity coefficients, the number of charging EVs responding to the RTOU electricity price is calculated as follows:

$$
N_{t}^{j}=N 0_{t}^{j}+\sum_{h=1}^{M} \Delta N_{t}^{j h}=N 0_{t}^{j}+\sum_{h=1}^{M} N 0_{t}^{j} \varepsilon_{t}^{j h} \frac{\Delta \rho_{t}^{j j}}{\rho_{0}}
$$

To quantify the elasticity coefficients, the triangular fuzzy number [29] is introduced:

$$
\varepsilon=\left\langle\begin{array}{lll}
\underline{\varepsilon} & \varepsilon & \bar{\varepsilon}
\end{array}\right\rangle
$$

where the fuzzy center $\varepsilon$ represents the average elasticity coefficient; $\underline{\varepsilon}$ and $\bar{\varepsilon}$ are the minimum and maximum price elasticity coefficients, respectively. The minimum and maximum number of EVs charging $N_{t}^{j}$ and $\overline{N_{t}^{j}}$ at time $t$ in zone $j$ are obtained by Equation (11) with the minimum and maximum current regional coefficient $\varepsilon_{t}^{j j}$ and other regional elasticity coefficients $\varepsilon_{t}^{j h}$.

\section{The Bi-Layer Optimization Strategy for EVs Charging}

\subsection{The Framework of the Optimal Charging Strategy for EVS}

The framework of the proposed optimal charging strategy for EVs is shown in Figure 3. 


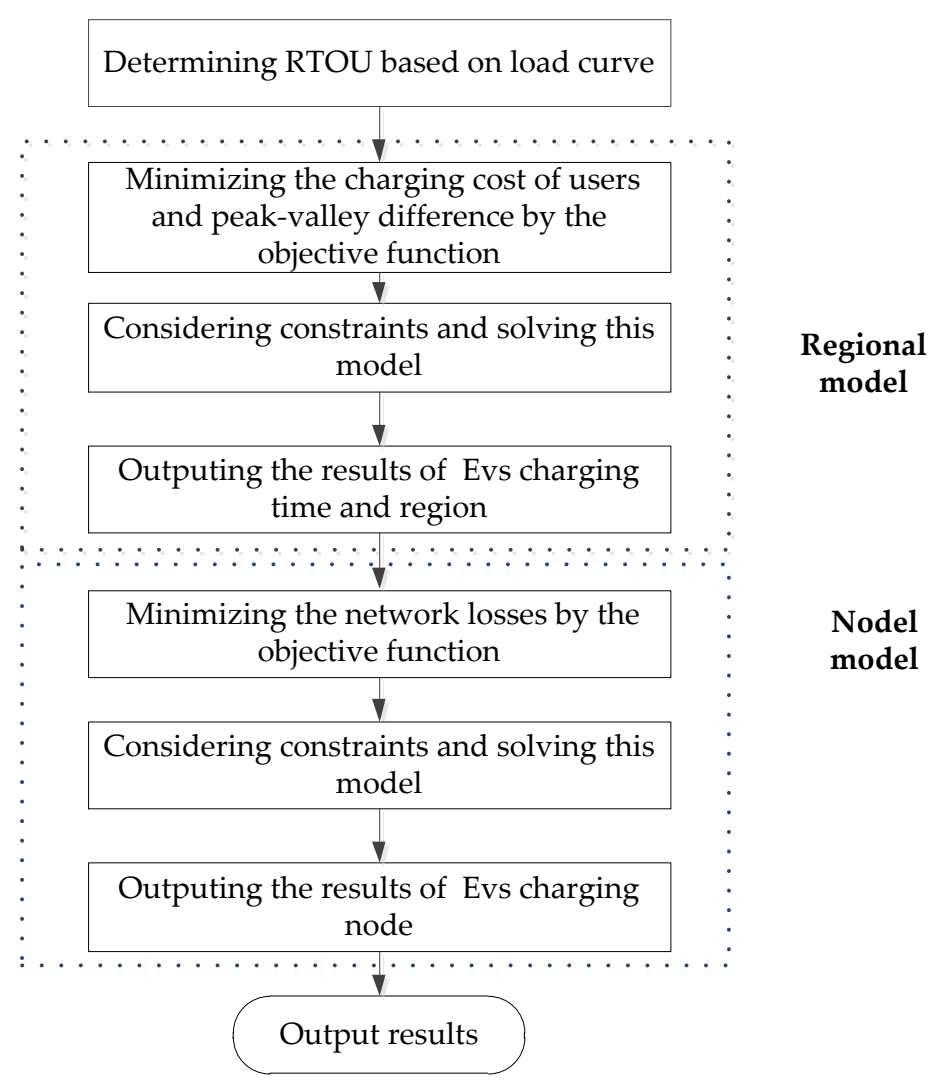

Figure 3. The framework of the optimal charging strategy for EVs.

\subsection{Regional Layer Model}

The regional layer model is to minimize the charging cost of EV users and alleviate the peak-valley difference in the distribution network by coordinating the EVs at different time and space. The outputs of the regional layer model are the charging cost and peak-valley difference by guiding the charging time and charging region of the EVs.

\subsubsection{Objective Function}

\section{Charging cost of users}

Regarding the fact that the charging cost of users is selected as the objective function, its expression is:

$$
f_{1}=\min \sum_{j=1}^{M} \sum_{t=1}^{T}\left(\rho_{t}^{j} P_{c} N_{t}^{j} \Delta t\right)
$$

where $P_{c}$ is the average charging power of EVs. $\Delta t$ is the length of time interval, and herein it is set as one hour.

2. Peak-valley difference

To realize the economic operation of the power grid, the peak valley difference is also considered as an optimal objection [30]:

$$
f_{2}=\min \left(L_{\max }-L_{\min }\right)
$$

where $L_{\max }$ and $L_{\min }$ are the peak load and valley load, respectively.

A linear weighting method is used to calculate the multi-objective function:

$$
F=\min \left(\lambda_{1} \frac{f_{1}}{f_{10}}+\lambda_{2} \frac{f_{2}}{f_{20}}\right)
$$


where $F$ is the total objective function. $\lambda_{1}$ and $\lambda_{2}$ are the weight coefficients, respectively. $f_{10}$ and $f_{20}$ is the base charging cost and the peak-valley difference to elimination physical dimension. The value of $\lambda_{1}$ and $\lambda_{2}$ can be determined by balancing the interests of the grid and the users, and herein $\lambda_{1}=0.5$ and $\lambda_{2}=0.5$ are adopted.

\subsubsection{Constraints}

1. Constraint of charging hours

To charge sufficient energy to EVs, the charging time should be long enough:

$$
\sum_{j=1}^{M} \sum_{t=1}^{T} N_{t}^{j} \geq N_{\max } \Delta t_{c}
$$

where $\Delta t_{c}$ is the average charging time of EVs, and $N_{\max }$ is the maximum number of available charging EVs.

2. Constraint of total EVs number in the zone

The number of available charging EVs in the zone at every time can be constrained as follows:

$$
\begin{gathered}
\sum_{j=1}^{M} N_{t}^{j} \leq N_{\max } \quad \forall t \in T \\
N_{t}^{j} \leq Q_{j}
\end{gathered}
$$

3. Constraint of user responsivity

After adjusting the electricity price, some EVs will be guided to charge in special charging stations, and meanwhile there are still some EVs that do not respond to the RTOU electricity price. According to the user responsivity model suggested in Section 3, the constraint of user responsivity to the RTOU electricity price can be constrained as follows:

$$
\underline{N_{t}^{j}} \leq N_{t}^{j} \leq \overline{N_{t}^{j}}
$$

\subsection{Node Layer Model}

The node layer model optimization is to minimize the loss of the distribution network. Meanwhile, the profits of the users and charging station are taken into consideration [31]. The outputs of the node layer model are the EVs' charging node and network loss by guiding the charging node of EVs.

\subsubsection{Objective Function}

For the objective function related to the power loss, it is expressed as:

$$
f_{3}=\min \sum_{t=1}^{T} P_{\text {Loss }, t}
$$

where $P_{\text {Loss, },}$ is denoted as:

$$
P_{\text {Loss }, t}=\sum_{k=1}^{K} \sum_{m=1}^{K} 0.5 *\left(\left|V_{k, t}\right|^{2} G_{k m}+\left|V_{m, t}\right|^{2} G_{k m}-2\left|V_{k, t}\right|\left|V_{m, t}\right| G_{k m} \cos \theta_{k m, t}\right)
$$

where $K$ is the set of all nodes except slack node. $V_{k, t}$ and $V_{m, t}$ are the voltages of node $k$ and node $m$, respectively. $G_{k m}$ is the real part of admittance matrix; $\theta_{k m, t}$ is the phase angle difference between node $k$ and node $m$ at time $t$. 


\subsubsection{Constraints}

1. Constraint of active and reactive power balance

The active and reactive power balance must be satisfied at each node:

$$
\begin{gathered}
P_{k, t}^{G}-P_{k, t}^{D}-P_{c} N_{t}^{k}-P_{k, t}^{T}=0 \quad \forall k \in K, \forall t \in T \\
Q_{k, t}^{G}-Q_{k, t}^{D}-Q_{k, t}^{T}=0 \quad \forall k \in K, \forall t \in T
\end{gathered}
$$

where $P_{k, t}^{G}$ and $Q_{k, t}^{G}$ are the active and reactive power of node $k$ at time $t$, respectively. $P_{k, t}^{D}$ and $Q_{k, t}^{D}$ are the active and reactive power load of node $k$ at time $t$, respectively. $P_{k, t}^{T}$ and $Q_{k, t}^{T}$ are the transmitted active and reactive power of node $k$ at time $t$, respectively:

$$
\begin{aligned}
& P_{k, t}^{T}=V_{k, t} \sum_{m \in K} V_{m, t}\left(G_{k m} \cos \theta_{k m, t}+B_{k m} \sin \theta_{k m, t}\right) \\
& Q_{k, t}^{T}=V_{k, t} \sum_{m \in K} V_{m, t}\left(G_{k m} \sin \theta_{k m, t}-B_{k m} \cos \theta_{k m, t}\right)
\end{aligned}
$$

where $B_{k m}$ is the imaginary part of admittance matrix.

2. Constraint of node voltage

The node voltage should meet the following constraint conditions:

$$
V_{k, \min } \leq V_{k, t} \leq V_{k, \max } \quad \forall k \in K, \forall t \in T
$$

where $V_{k, \min }$ and $V_{k, \max }$ are the lower and upper limits of node voltage, respectively.

\section{Constraint of security}

To ensure the security of the distribution network, the transmission capacities of lines must be limited in a safe range:

$$
\left|P_{k m, t}\right| \leq P_{k m, \max } \quad \forall k \in K, \forall t \in T
$$

where $P_{k m, \max }$ is the maximum transmission capacity of line $k-m$, and $P_{k m, t}$ is the power flow of transmission line $k-m$ at time $t$ :

$$
\left|P_{k m, t}\right|=\left|V_{k, t} V_{m, t}\left(G_{k m} \cos \theta_{k m, t}+B_{k m} \sin \theta_{k m, t}\right)-V_{k, t} G_{k m}\right|
$$

4. Constraint of charging station revenue

After the RTOU electrical price is used, the revenues of the charge stations are not less than before:

$$
S_{k}= \begin{cases}\geq 1 & N_{t}^{k}>0 \\ 0 & N_{t}^{k}=0\end{cases}
$$

where $S_{k}$ is the revenue coefficient of the charge station accessed to node $k$ :

$$
S_{k}=\frac{C}{C_{0}} \times 100 \%=\frac{\sum_{t=1}^{T} \rho_{t}^{j} P_{c} N_{t}^{k} \Delta t}{\rho_{0} \sum_{t=1}^{T} P_{c} N_{t}^{k} \Delta t}
$$

where $C$ and $C_{0}$ are the revenues with and without the RTOU electrical price, respectively.

5. Constraint for the total number of EVs in the regional 
The number of available charging EVs in a certain zone can be constrained as follows:

$$
\sum_{k \in j} N_{t}^{k}=N_{t}^{j} \quad \forall t \in T
$$

6. Constraint of charging station service capacity

The EV charging stations are divided into four different grades [32]:

$$
N_{t}^{k} \leq Q_{k}
$$

\section{Case Studies}

In this section, numeral simulations are carried out to illustrate the effectiveness of the proposed charging strategy for EVs. As shown in Figure 4, an IEEE 33-bus distribution network is divided into four regions consisting of an industrial zone, a commercial zone, a residential zone and an office zone. Node 0 in the IEEE 33-bus system is a slack bus. In this distribution system, the base power is set as 100 MVA and the base voltage is set as $12.66 \mathrm{kV}$. The parameters of lines and the maximum load of nodes are obtained from literature [33].

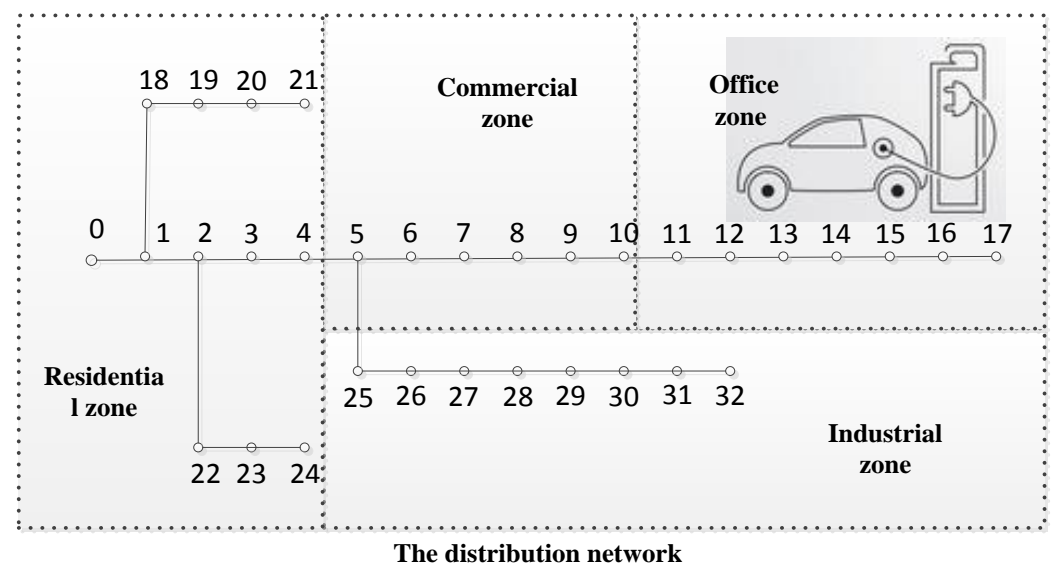

Figure 4. An IEEE 33-bus distribution network.

During the simulations, $\rho_{1}$ is set as $0.55 \mathrm{CNY} / \mathrm{kWh} ; \rho_{2}$ is set as $0.60 \mathrm{CNY} / \mathrm{kWh} ; \rho_{3}$ is set as $0.65 \mathrm{CNY} / \mathrm{kWh} ; \rho_{4}$ is set as $0.70 \mathrm{CNY} / \mathrm{kWh}$. The TOU electricity price and the RTOU electricity price are shown in Figures 5 and 6, respectively.

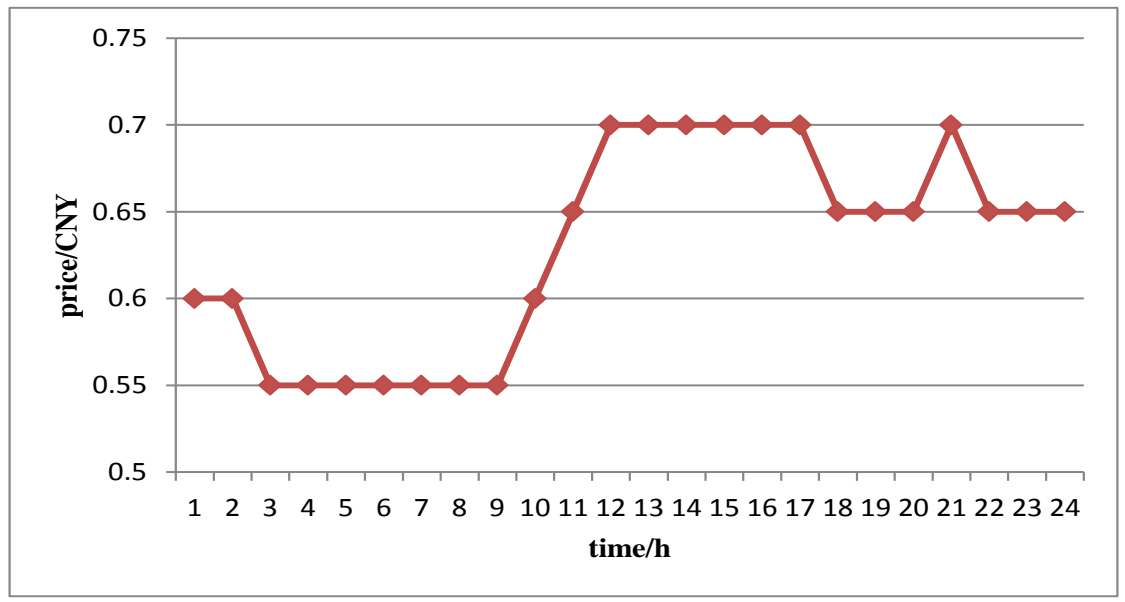

Figure 5. The TOU electricity price profile. 


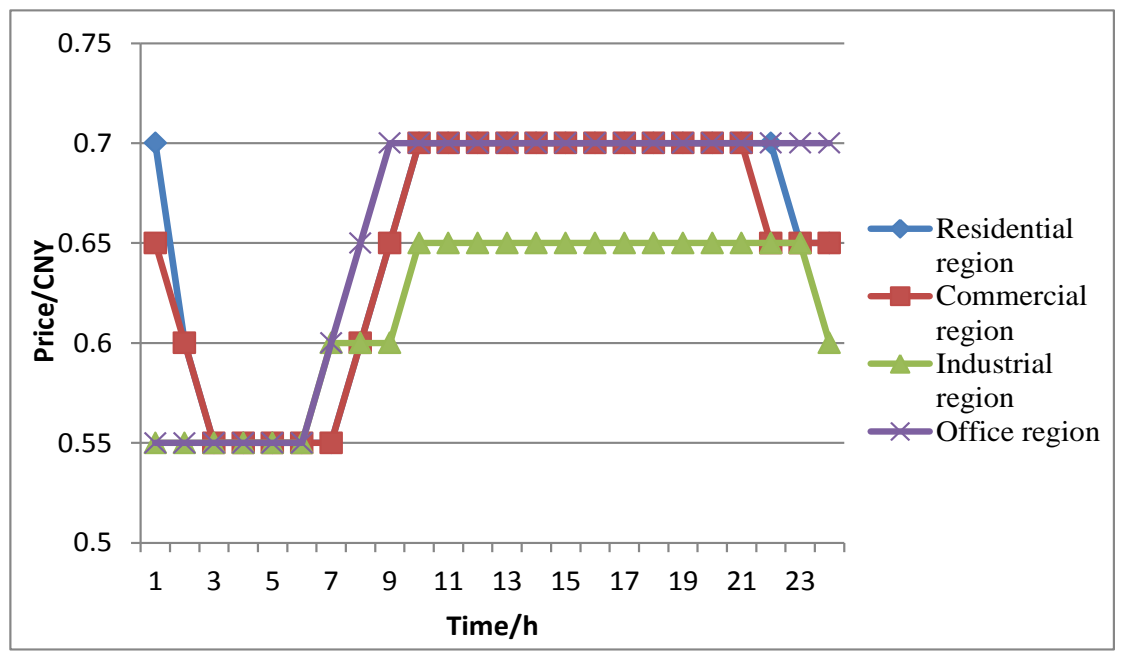

Figure 6. The RTOU electricity price profiles.

\subsection{Optimization Results of the Regional Layer Model}

Four cases are studied in this section as follows:

Case 1: there are $1200 \mathrm{EVs}$ with uncontrolled charging mode, and the electricity price of charging in this case is set as $0.65 \mathrm{CNY} / \mathrm{kWh}$.

Case 2: there are 1200 EVs charging with the proposed optimization strategy, and the user responsivity is considered. The price profiles of charging in this case are shown in Figure 6.

Case 3: there are 1200 EVs charging with the proposed optimization strategy, and the user responsivity isn't considered. The price profiles of charging in this case are shown in Figure 6.

Case 4: there are 1200 EVs charging with the proposed optimization strategy, and the user responsivity is considered. The price profiles of charging in this case are shown in Figure 5. Compared with user responsivity to the RTOU electricity price, the phenomenon of EVs charging in the cross-region can be ignored.

The optimization of the regional model is a mixed-integer linear programming (MILP) problem which can be solved by the GMP-CPLEX solver in AIMMS [34]. The expectations of the objective function, peak-valley difference and charging cost for four cases are shown in Table 2, and the load curves are shown in Figure 7. Compared with case 1, the peak-valley difference and the user charging cost are decreased in cases 2,3,4. Without considering user responsivity in case 3 , the performance of the peak-valley difference and the user charging cost will be better than that in case 2, because all the EVs are dispatched to charge by the RTOU electricity price. Compared with case 4 using the TOU electricity price, the optimal results of case 2 using the RTOU electricity price will be better.

Table 2. The simulation results of EVs optimization.

\begin{tabular}{ccccc}
\hline Case & Case 1 & Case 2 & Case 3 & Case 4 \\
\hline peak-valley difference (MW) & 11.43 & 10.725 & 8.07 & 10.437 \\
charging cost (CNY) & 14,500 & 13,600 & 12,100 & 14,200 \\
objective function & 2.35 & 2.21 & 1.82 & 2.24 \\
\hline
\end{tabular}

The optimization results in the regional layer model are shown in Figure 8. Compared to the random charging behaviors of EVs in case 1, the optimized charging loads of EVs are concentrated 
at the time when the basic load and electricity price are small in cases $2-4$. The impacts of user responsivity on EVs schedule are compared between case 2 and case 3. Without considering user responsivity in case 3, the total charging loads of EVs may concentrate during 1:00 a.m.-7:00 a.m. However, partial EVs prefer to charge at 8:00 a.m.-10:00 a.m. and 17:00 p.m.-19:00 p.m. in case 2. The impacts of different price profiles on EVs scheduling are compared between case 2 and case 4 . Compared with case 2 using the RTOU electricity price, more EVs charging load concentrates at the time when the electricity price is small.

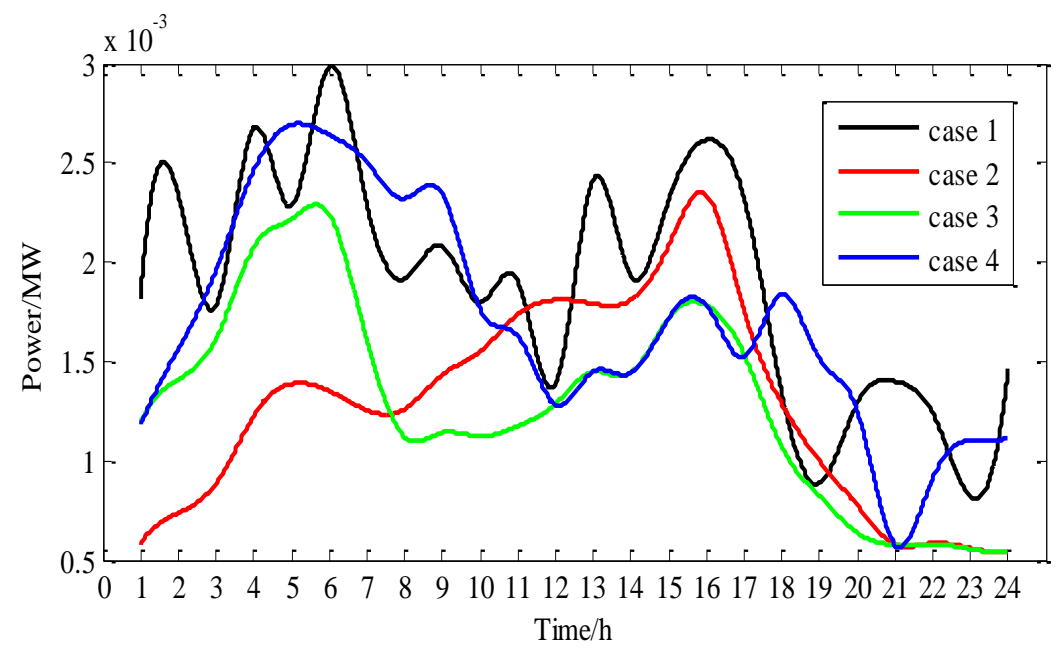

Figure 7. The load curves before and after the regional dispatch.

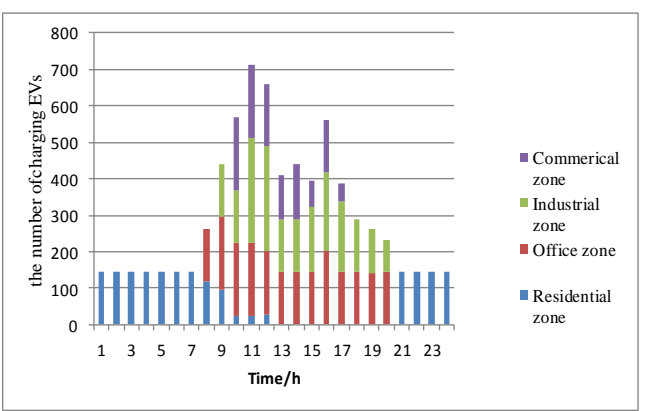

(a)

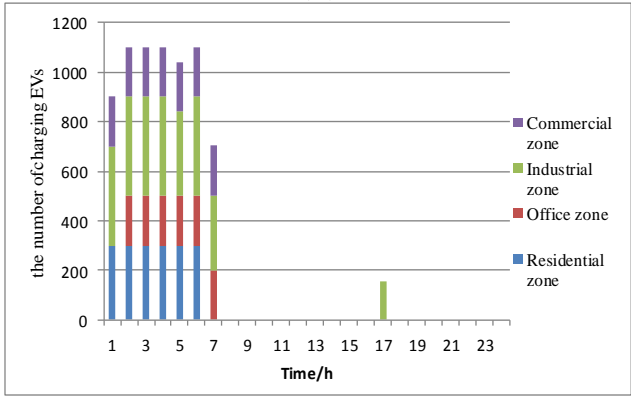

(c)

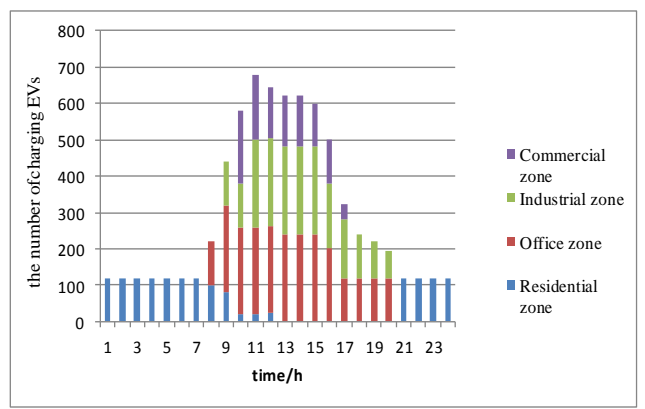

(b)

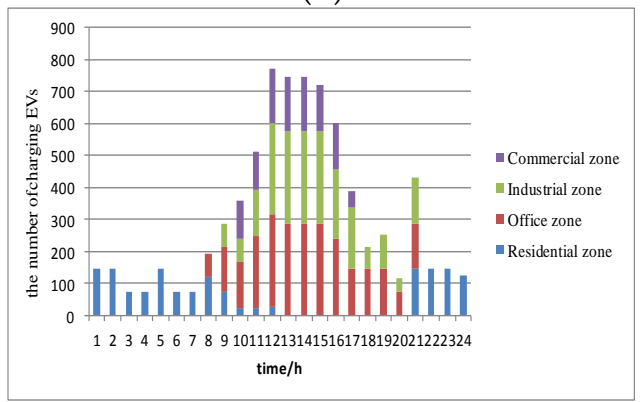

(d)

Figure 8. The optimization results of the regional dispatch for EVs. There are four panels, they should be listed as: (a) Case 1; (b) Case 2; (c) Case 3; (d) Case 4.

The regional simulation results are analyzed when different RTOU electricity prices and price elasticity coefficients are considered, so as to verify this paper's viewpoint.

When $\rho_{1}$ is set as $0.5 \mathrm{CNY} / \mathrm{kWh} ; \rho_{2}$ is set as $0.65 \mathrm{CNY} / \mathrm{kWh} ; \rho_{3}$ is set as $0.75 \mathrm{CNY} / \mathrm{kWh} ; \rho_{4}$ is set as $0.90 \mathrm{CNY} / \mathrm{kWh}$, the simulation results of the four cases are shown as Figure 9. 


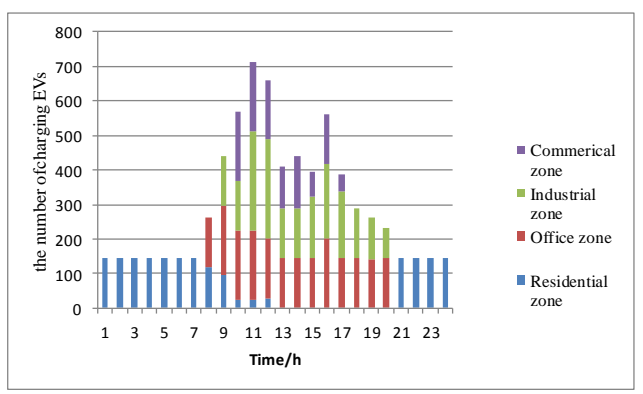

(a)

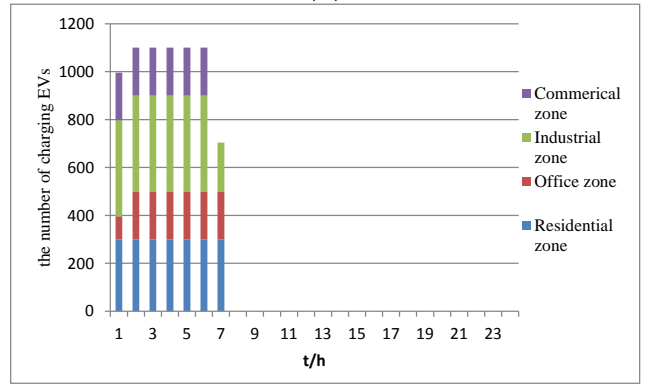

(c)

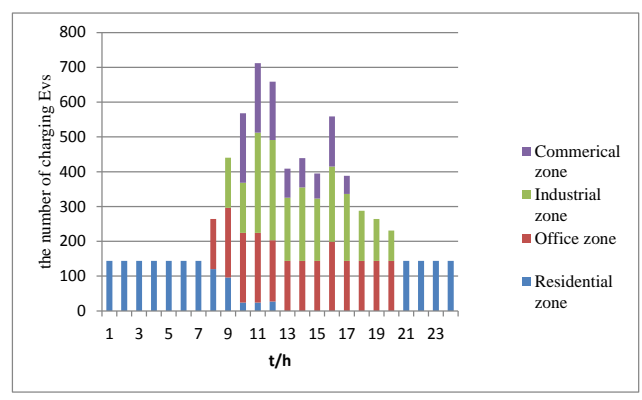

(b)

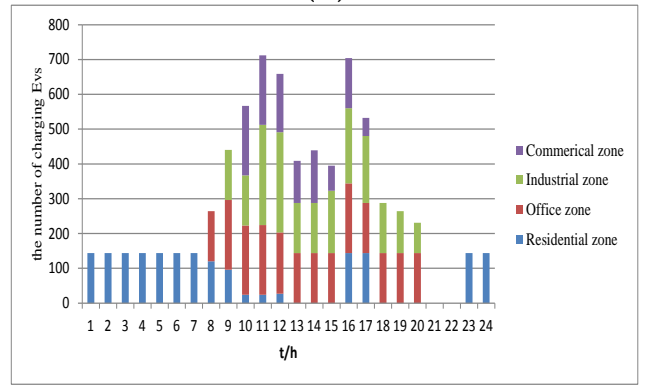

(d)

Figure 9. The optimization results of different RTOU electricity prices. There are four panels, they should be listed as: (a) Case 1; (b) Case 2; (c) Case 3; (d) Case 4.

From Table 3, it is concluded that the change of tariff may only affect the specific values of scheduling results, but not change the qualitative conclusions shown in this paper. When driving habits, SOC of batteries and external environment change, the number of responsive EVs will change accordingly. In this paper, it means that the price elasticity coefficients will change. Table 4 shows the simulation results of different price elasticity coefficients. In Table 4 , the change of price elasticity coefficients may only affect the specific values of scheduling results, but not change the qualitative conclusions. Moreover, driving habits, SOC of batteries and external environment have no effect on the proposed scheduling strategy.

Table 3. The simulation results of different RTOU electricity prices.

\begin{tabular}{ccccc}
\hline Case & Case 1 & Case 2 & Case 3 & Case 4 \\
\hline peak-valley difference $(\mathrm{MW})$ & 11.43 & 9.97 & 8.07 & 10.7 \\
charging cost $(\mathrm{CNY})$ & 14,500 & 12,920 & 12,100 & 13,400 \\
objective function & 2.53 & 2.07 & 1.82 & 2.18 \\
\hline
\end{tabular}

Table 4. The simulation results of different price elasticity coefficients.

\begin{tabular}{ccccc}
\hline Case & Case 1 & Case 2 & Case 3 & Case 4 \\
\hline peak-valley difference (MW) & 11.43 & 10.525 & 6.67 & 10.72 \\
charging cost (CNY) & 16,700 & 12,960 & 12,300 & 13,800 \\
objective function & 2.35 & 2.13 & 1.69 & 2.22 \\
\hline
\end{tabular}

\subsection{The Optimization Results of the Node Layer Model}

Four cases are studied in this section as follows:

Case 5: The number of EVs charging in the four regions is the same as case 1, and the charging behaviors of EVs are uncontrolled.

Case 6: The number of EVs charging in the four regions is the optimization results in case 2.

Case 7: The number of EVs charging in the four regions is the optimization results in case 3. 
Case 8: The number of EVs charging in the four regions is the optimization results in case 4.

The optimization problem is a mixed-integer nonlinear programming (MINLP) which can be solved by the GMP-AOA solver in AIMMS [34]. The optimization results in the node layer model are shown in Figure 10. Figure 11 shows the EVs spatial distribution at 10:00 a.m. in case 6. From Figures 10 and 11, the conclusion can be drawn that the optimized spatial charging distributions of EVs are concentrated in the nodes $1,18,5,6,11,12,13,25,26,27$ and 28 close to the beginning bus of each region. Thus, if the charging stations are located in the aforementioned nodes, the network losses caused by EVs charging loads can be well reduced.

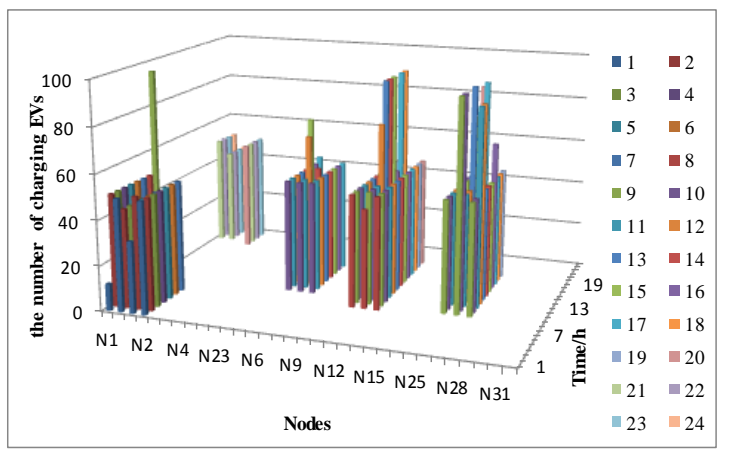

(a)

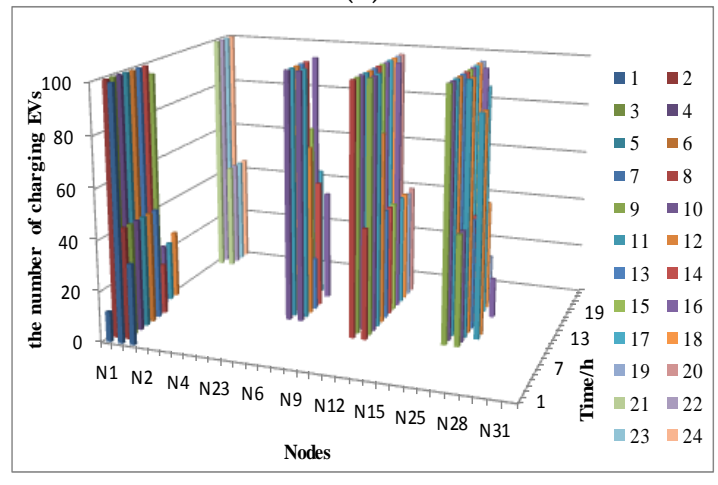

(c)

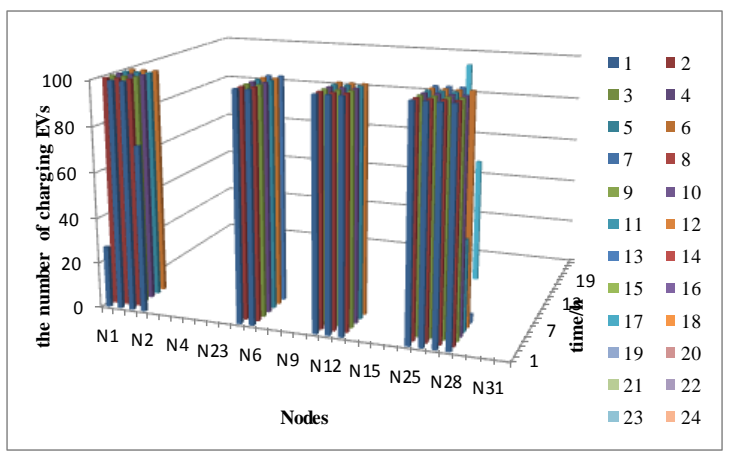

(b)

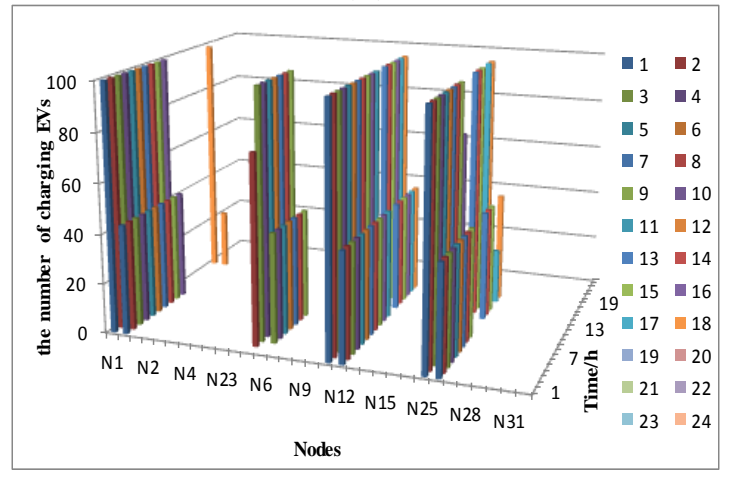

(d)

Figure 10. The optimization results of node dispatch for EVs. There are four panels, they should be listed as: (a) Case 5; (b) Case 6; (c) Case 7; (d) Case 8.

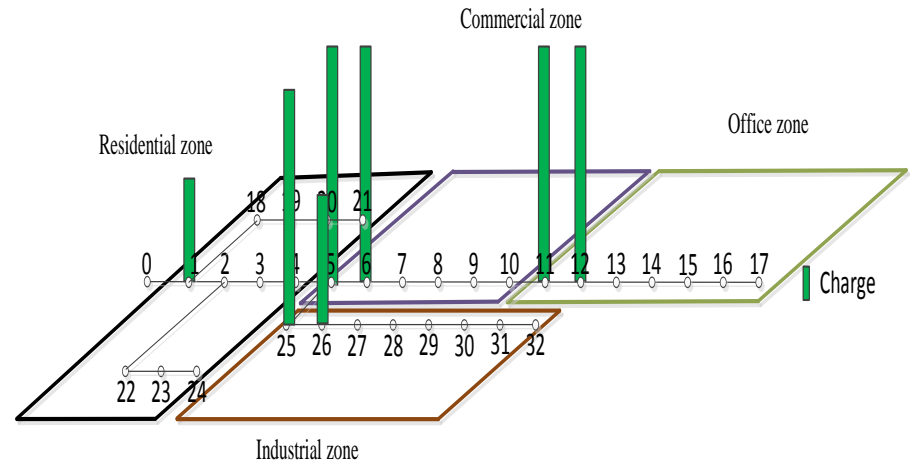

Figure 11. The spatial distributions of EVs charging at 10 a.m. in case 6 in the network.

Figure 12 shows the network losses before and after optimization. The total network losses in case 5, case 6, case 7 and case 8 will be $0.0453 \mathrm{MW}, 0.0303 \mathrm{MW}, 0.0309 \mathrm{MW}$, and $0.0406 \mathrm{MW}$, respectively. Regarding case 2 and case 3 where user responsivity are respectively considered and ignored, their impacts on case 6 and case 7 are analyzed, respectively. Since the more concentration of 
EVs charging loads in time-domain in case 3 causes the loads decentralization in spatial domain, the optimization results in case 6 show better performance than that in case 7 . For case 2 and case 4 where the RTOU electricity price and the TOU electricity price are adopted, respectively, their impacts on the node layer model are analyzed in case 6 and case 8 . From the figure, the total network losses in case 6 are smaller than that in case 8 . In addition, the curves of the network losses have different peak time, and the reason is that the temporal distribution of charging EVs is different in the four cases.

Figure 13 shows the voltage distributions under different cases. Compared with case 5, it is found that case 6 , case 7 and case 8 will show better performance on the voltage levels of end nodes. Regarding case 2 and case 3 where user responsivity are respectively considered and ignored, their impacts on case 6 and case 7 are studied, respectively.

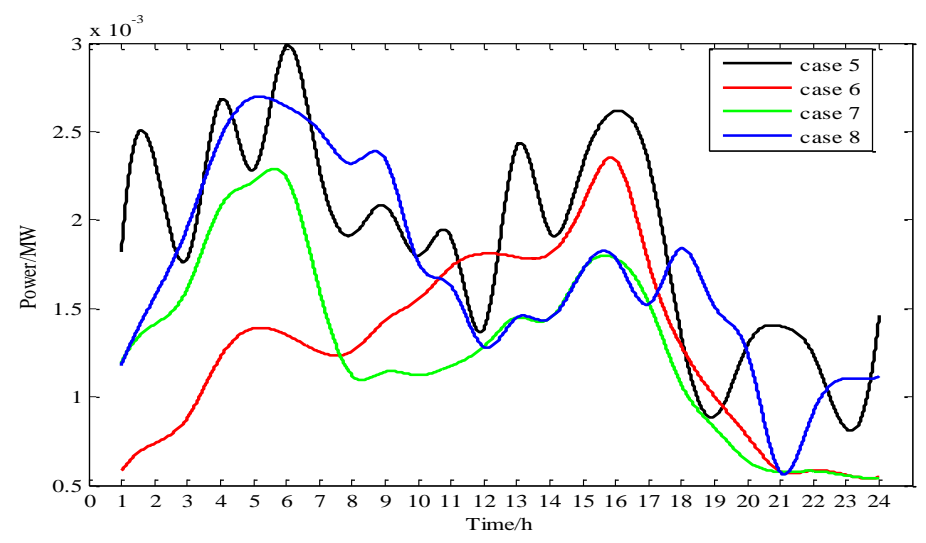

Figure 12. The network losses before and after optimization dispatch.

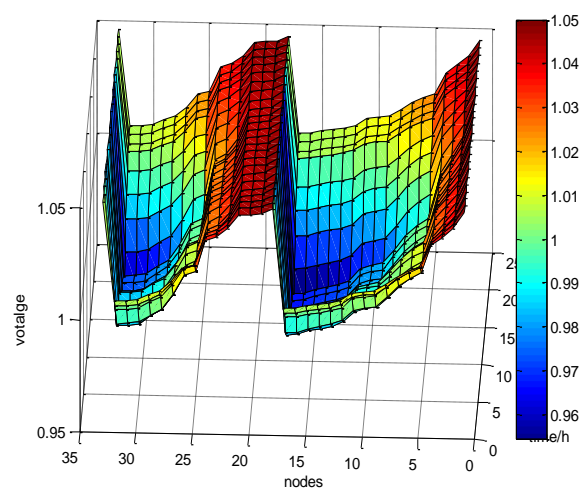

(a)

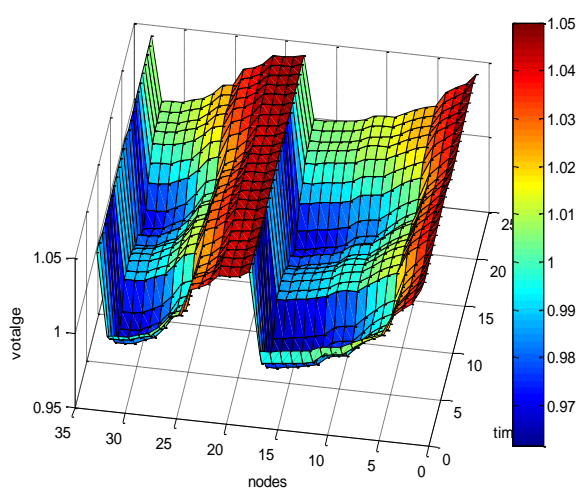

(c)

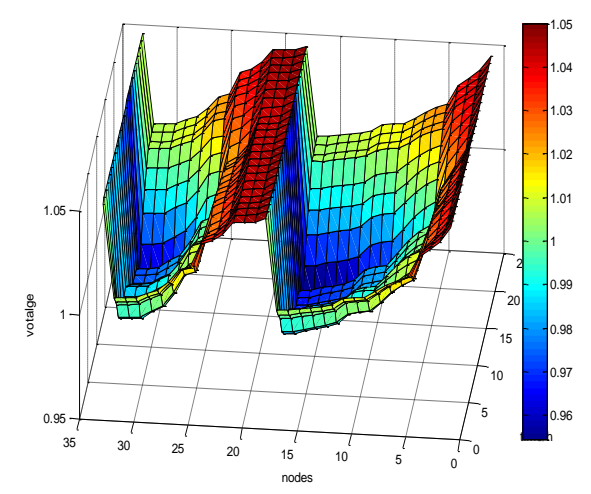

(b)

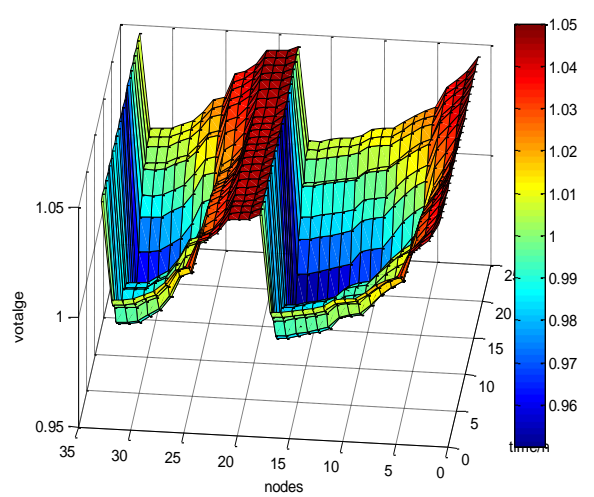

(d)

Figure 13. The voltage distributions of the distribution network. There are four panels, they should be listed as: (a) Case 5; (b) Case 6; (c) Case 7; (d) Case 8. 
In view of that the more concentration of EVs charging loads in time-domain in case 3 causes the loads decentralization in spatial domain, the optimization results in case 6 show better performance than that in case 7 . For case 2 and case 4 where the RTOU electricity price and the TOU electricity price are used, respectively, their impacts on the node layer model are analyzed in case 6 and case 8. It is observed that, the voltage levels of end nodes in case 6 are more preferable.

\section{Conclusions}

This paper's main contribution is to propose a RTOU electricity price-based bilayer optimization charging strategy for EVs, and herein the benefits of distribution network and users are both taken into account. To analyze the impacts of the RTOU electricity price on the charging behaviors of EVs, the user responsivity is investigated by the method of elastic coefficient. From the simulations of an IEEE 33-bus distribution network, the performance of the proposed optimal charging strategy is verified, and some conclusions are drawn as follows:

(1) The effectiveness of the proposed optimization charging strategy can be confirmed. For the regional layer model which is designed to coordinate the EVs located in different time and space, it can shave the peak and fill the valley of load profiles, and the charging cost of users is well reduced. Concerning the node layer model which is built to schedule the EVs to charge in certain nodes, its application can decrease the network losses to a certain extent.

(2) Compared with the TOU electricity price, the RTOU electricity price can obtain better optimization results.

(3) When the user responsivity to the RTOU electricity price is taken into consideration, the optimal scheduling results are more similar to reality.

(4) If the charging stations are located in the nodes being close to the beginning bus of each region, the distribution network can potentially obtain better economic benefits.

In the near future, the optimal RTOU electricity price, real time tariff and feasible incentive measures will be studied further. Besides, some follow-up works related to the node layer model will be performed, and the EVs' scheduling strategy based on the integration of transportation network and power grid will be taken into account. The results will be reported in later articles.

Acknowledgments: The work is funded by the National Science Foundation of China (51277135, 50707021, and 51507117), State Grid Corporation of China (52020116000K) and the Fundamental Research Funds for the Central Universities (2042015kf1004).

Author Contributions: Jun Yang conceived the structure and research direction of the paper; Jiejun Chen wrote the paper and completed the simulation for case studies; Lei Chen revised the writing of the entire manuscript; Feng Wang provided algorithms; Peiyuan Xie wrote programs; Cilin Zeng analyzed the data.

Conflicts of Interest: The authors declare no conflict of interest.

\section{Abbreviations}

Index:

$t, s \quad$ Set of time

$j, h \quad$ Set of region

$k, m \quad$ Set of Nodes

\section{List of Main Variables:}

$\begin{array}{ll}N_{t}^{j} & \text { Number of charging EVs at time } t \text { in region } j \\ N_{t}^{k} & \text { Number of charging EVs at time } t \text { in node } k \\ V_{t}^{k} & \text { Voltage in node } k \\ P_{\text {Loss, } t} & \text { Network loss of distribution network at time } t\end{array}$




\section{List of Main Parameters:}

$\rho_{t}^{j} \quad$ Electricity price at time $t$ in region $j$

$Q_{j} \quad$ Maximum number of available charging EVs in region $j$

$Q_{k} \quad$ Service capacity of charging station in node $k$

$P_{k m, t} \quad$ Power flow on transmission line $k-m$ at time $\mathrm{t}$

\section{References}

1. Graditi, G.; Langella, G.; Laterza, C.; Valenti, M. Conventional and electric vehicles: A complete economic and environmental comparison. In Proceedings of the ICCEP 2015, 5th International Conference on Clean Electrical Power, Taormina, Italy, 16-18 June 2015; pp. 660-665.

2. Foley, A.; Tyther, B.; Calnan, P.; Gallachóir, B.Ó. Impacts of Electric Vehicle charging under electricity market operations. Appl. Energy 2013, 101, 93-102. [CrossRef]

3. Fernandes, C.; Frías, P.; Latorre, J.M. Impact of vehicle-to-grid on power system operation costs: The Spanish case study. Appl. Energy 2012, 96, 194-202. [CrossRef]

4. Sortomme, E.; Hindi, M.M.; MacPherson, S.J.; Venkata, S.S. Coordinated charging of plug-in hybrid electric vehicles to minimize distribution system losses. IEEE Trans. Smart Grid 2011, 2, 198-205. [CrossRef]

5. Lopes, J.A.P.; Soares, F.J.; Almeida, P.M.R. Integration of electric vehicles in the electric power system. Proc. IEEE 2011, 99, 168-183. [CrossRef]

6. Di Silvestre, M.L.; Sanseverino, E.R.; Zizzo, G.; Graditi, G. An optimization approach for efficient management of EV parking lots with batteries recharging facilities. J. Ambient Intell. Hum. Comput. 2013, 4, 641-649. [CrossRef]

7. Zakariazadeh, A.; Jadid, S.; Siano, P. Multi-objective scheduling of electric vehicles in smart distribution system. Energy Convers. Manag. 2014, 79, 43-53. [CrossRef]

8. Yang, J.; He, L.; Fu, S. An improved PSO-based charging strategy of electric vehicles in electrical distribution grid. Appl. Energy 2014, 128, 82-92. [CrossRef]

9. Yao, Y.; Gao, W.; Li, Y. Optimization of PHEV Charging Schedule for Load Peak Shaving. In Proceedings of the ITEC Asia-Pacific 2014 Conference-Expo, Beijing, China, 31 August-3 September 2014; pp. 1-6.

10. Tian, W. Electric Vehicle Battery Swapping Station Coordinated Charging Dispatch Method Based on Temporal and Spatial Double Dimensions. Ph.D. Thesis, Beijing Jiao Tong University, Beijing, China, 2013.

11. Deilami, S.; Masoum, A.S.; Moses, P.S.; Masoum, M.A. Real-time coordination of plug-in electric vehicle charging in smart grids to minimize power losses and improve voltage profile. IEEE Trans. Smart Grid 2011, 2, 456-467. [CrossRef]

12. Richardson, P.; Flynn, D.; Keane, A. Optimal charging of electric vehicles in low-voltage distribution systems. IEEE Trans. Power Syst. 2012, 27, 268-279. [CrossRef]

13. Yagcitekin, B.; Uzunoglu, M. A double-layer smart charging strategy of electric vehicles taking routing and charge scheduling into account. Appl. Energy 2016, 167, 407-419. [CrossRef]

14. He, L.; Yang, J.; Yan, J.; Tang, Y.; He, H. A bi-layer optimization based temporal and spatial scheduling for large-scale electric vehicles. Appl. Energy 2016, 168, 179-192. [CrossRef]

15. Rotering, N.; Ilic, M. Optimal charge control of plug-in hybrid electric vehicles in deregulated electricity markets. IEEE Trans. Power Syst. 2011, 26, 1021-1029. [CrossRef]

16. Xi, X.; Sioshansi, R. Using Price-Based Signals to Control Plug-in Electric Vehicle Fleet Charging. Smart Grid 2014, 3, 1451-1464. [CrossRef]

17. Shaoyun, G.; Huang, L.; Liu, H. Optimization of peak-valley TOU power price time-period in ordered charging mode of electric vehicle. Power Syst. Prot. Control 2012, 40, 1-5.

18. Ferruzzi, G.; Graditi, G.; Rossi, F.; Russo, A. Optimal operation of a residential microgrid: The role of demand side management. Intell. Ind. Syst. 2015, 1, 61-82. [CrossRef]

19. Dubey, A.; Santoso, S.; Cloud, M.P.; Waclawiak, M. Determining Time-of-Use Schedules for Electric Vehicle Loads: A Practical Perspective. Power Energy Technol. Syst. J. 2015, 2, 12-20. [CrossRef]

20. Cao, Y.; Tang, S.; Li, C.; Zhang, P.; Tan, Y.; Zhang, Z.; Li, J. An optimized EV charging model considering TOU price and SOC curves. IEEE Trans. Smart Grid 2012, 3, 388-393. [CrossRef]

21. Soltani, N.Y.; Kim, S.J.; Giannakis, G.B. Real-time load elasticity tracking and pricing for electric vehicle charging. IEEE Trans. Smart Grid 2015, 6, 1303-1313. [CrossRef] 
22. He, Y.; Venkatesh, B.; Guan, L. Optimal scheduling for charging and discharging of electric vehicles. IEEE Trans. Smart Grid 2012, 3, 1095-1105. [CrossRef]

23. Yan, Q.; Manickam, I.; Kezunovic, M.; Xie, L. A multi-tiered real-time pricing algorithm for electric vehicle charging stations. In Proceedings of the ITEC 2014, IEEE Transportation Electrification Conference and Expo, China, Beijing, 31 August 2014; pp. 1-6.

24. Song, Y. Optimzation Model for the Design of Tired Pricing for Household Electricity in China. Master's Thesis, North China Electric Power University, Beijing, China, 2011.

25. Arks, K.; Denholm, P.; Markel, A.J. Costs and Emissions Associated with Plug-in Hybrid Electric Vehicle Charging in the Xcel Energy Colorado Service Territory; National Renewable Energy Laboratory: Golden, CO, USA, 2007.

26. Li, R.; Wu, Q.; Oren, S. Distribution locational marginal pricing for optimal electric vehicle charging management. IEEE Trans. Syst. 2014, 29, 203-211. [CrossRef]

27. Falvo, M.C.; Graditi, G.; Siano, P. Electric vehicles integration in demand response programs. In Proceedings of the 2014 International Symposium on Power Electronics, Electrical Drives, Automation and Motion (SPEEDAM 2014), Ischia, Italy, 18-20 June 2014; pp. 548-553.

28. Koroleva, K.; Kahlen, M.; Ketter, W.; Rook, L.; Lanz, F. Tamago car: Using a simulation app to explore price elasticity of demand for electricity of electric vehicle users. In Proceedings of the International Conference on Information Systems, Auckland, New Zealand, 14-17 December 2014.

29. Li, Y.; Luo, Q.; Song, Y.Q.; Xu, J.; Cai, L.; Gu, J. Tiered pricing mechanism based on fuzzy demand response. East China Electr. Power 2012, 40, 367-372.

30. Bae, S.; Kwasinski, A. Spatial and temporal model of electric vehicle charging demand. IEEE Trans. Smart Grid 2012, 3, 394-403. [CrossRef]

31. Acha, S. Impacts of Embedded Technologies on Optimal Operation of Energy Service Networks. Ph.D. Thesis, Imperial College, London, UK, 2010.

32. Beijing Quality and Technology Supervision Bureau. Technical Specification of Electricity Supply and Assure for Electric Vehicle: Electric Vehicle Charging Station; DB11/Z728-2010; Beijing Quality and Technology Supervision Bureau: Beijing, China, 2010.

33. Venkatesh, B.; Ranjan, R.; Gooi, H.B. Optimal reconfiguration of radial distribution systems to maximize load ability. IEEE Trans. Power Syst. 2004, 19, 260-266. [CrossRef]

34. The AIMMS Website. 2014. Available online: http://aimms.com/english/developers/resources/solvers/ (accessed on 25 December 2014). 